\title{
THE
}

\section{Deep Sea Underwater Robotic Exploration in the Ice-Covered Arctic Ocean With AUVs}

\author{
Clayton Kunz \\ Chris Murphy \\ Richard Camilli \\ Hanumant Singh \\ John Bailey
}

See next page for additional authors

Follow this and additional works at: https://digitalcommons.uri.edu/gsofacpubs

Part of the Ocean Engineering Commons, Oceanography Commons, and the Robotics Commons Terms of Use

All rights reserved under copyright.

\section{Citation/Publisher Attribution}

Kunz, C., Murphy, C., Camilli, R., Singh, H., Bailey, J., Eustice, R., Jakuba, M., Nakamura, K., Roman, C., Sato, T., Sohn, R.A., \& Willis, C. (2008). Deep sea underwater robotic exploration in the ice-covered Arctic ocean with AUVs. Intelligent Robots and Systems, 2008. IROS 2008. IEEE/RSJ International Conference on, pp.3654-3660, 22-26 Sept.

Available at: http://dx.doi.org/10.1109/IROS.2008.4651097

This Article is brought to you for free and open access by the Graduate School of Oceanography at DigitalCommons@URI. It has been accepted for inclusion in Graduate School of Oceanography Faculty Publications by an authorized administrator of DigitalCommons@URI. For more information, please contact digitalcommons-group@uri.edu. 


\section{Authors}

Clayton Kunz, Chris Murphy, Richard Camilli, Hanumant Singh, John Bailey, Ryan M. Eustice, Chris Roman, Michael Jakuba, Claire Willis, Taichi Sato, Ko-ichi Nakamura, and Robert A. Sohn

This article is available at DigitalCommons@URI: https://digitalcommons.uri.edu/gsofacpubs/22 


\title{
Deep Sea Underwater Robotic Exploration in the Ice-Covered Arctic Ocean with AUVs
}

\author{
Clayton Kunz, Chris Murphy, Richard Camilli, Hanumant Singh, John Bailey, Ryan Eustice, \\ Chris Roman, Michael Jakuba, Claire Willis, Taichi Sato, Ko-ichi Nakamura, Robert A. Sohn
}

\begin{abstract}
The Arctic seafloor remains one of the last unexplored areas on Earth. Exploration of this unique environment using standard remotely operated oceanographic tools has been obstructed by the dense Arctic ice cover. In the summer of 2007 the Arctic Gakkel Vents Expedition (AGAVE) was conducted with the express intention of understanding aspects of the marine biology, chemistry and geology associated with hydrothermal venting on the section of the mid-ocean ridge known as the Gakkel Ridge.

Unlike previous research expeditions to the Arctic the focus was on high resolution imaging and sampling of the deep seafloor. To accomplish our goals we designed two new Autonomous Underwater Vehicles (AUVs) named Jaguar and Puma, which performed a total of nine dives at depths of up to $4062 \mathrm{~m}$. These AUVs were used in combination with a towed vehicle and a conventional CTD (conductivity, temperature and depth) program to characterize the seafloor. This paper describes the design decisions and operational changes required to ensure useful service, and facilitate deployment, operation, and recovery in the unique Arctic environment.
\end{abstract}

\section{INTRODUCTION}

Despite the singular biological, geological and physical oceanographic characteristics of the Arctic seafloor, it remains one of the least explored sections of the planet. The Gakkel Ridge, the focus of this expedition, is the Arctic continuation of the Mid-Oceanic Ridge system. The Gakkel Ridge has an ultra slow spreading center with the potential to provide unique insights into the nature of the Earth's mantle. Recent work has also found widespread hydrothermal venting along the Ridge. This fact, when coupled with the thirty million year geological isolation of the Arctic Ocean,

Manuscript received February 21, 2008, revised June 21, 2008. This work was made possible in part through NSF OPP grant OPP-0425838, through the NASA ASTEP program through grant Z601701, through NSF Censsis ERC through grant EEC-9986821 and through funding from the Woods Hole Oceanographic Institution.

C. Kunz, C. Murphy, R. Camilli, H. Singh, M. Jakuba, and J. Bailey are with the Deep Submergence Laboratory, Woods Hole Oceanographic Institution, Woods Hole, MA 02543 USA \{ckunz, cmurphy, rcamilli, hsingh, mjakuba, jbailey\} ewhoi.edu

R. Eustice is with the Department of Naval Architecture \& Marine Engineering, University of Michigan, Ann Arbor, MI 48109 USA eustice@umich.edu

C. Roman is with the Department of Oceanography, University of Rhode Island, Narragansett, RI 02882 USA cnregso.uri.edu

T. Sato is with the Ocean Research Institute, University of Tokyo, Nakano, Tokyo 164-8639, JAPAN taichix@ori.u-tokyo.ac.jp

C. Willis and R. Sohn are with the Department of Geology and Geophysics, Woods Hole Oceanographic Institution, Woods Hole, MA 02543 USA \{ccwillis, rsohn\}@whoi.edu

K. Nakamura is with the Geological Survey of Japan, Agency of Industrial Science and Technology, Tsukuba, 1-1-1 Higa JAPAN koichi.nakamura@aist.go.jp

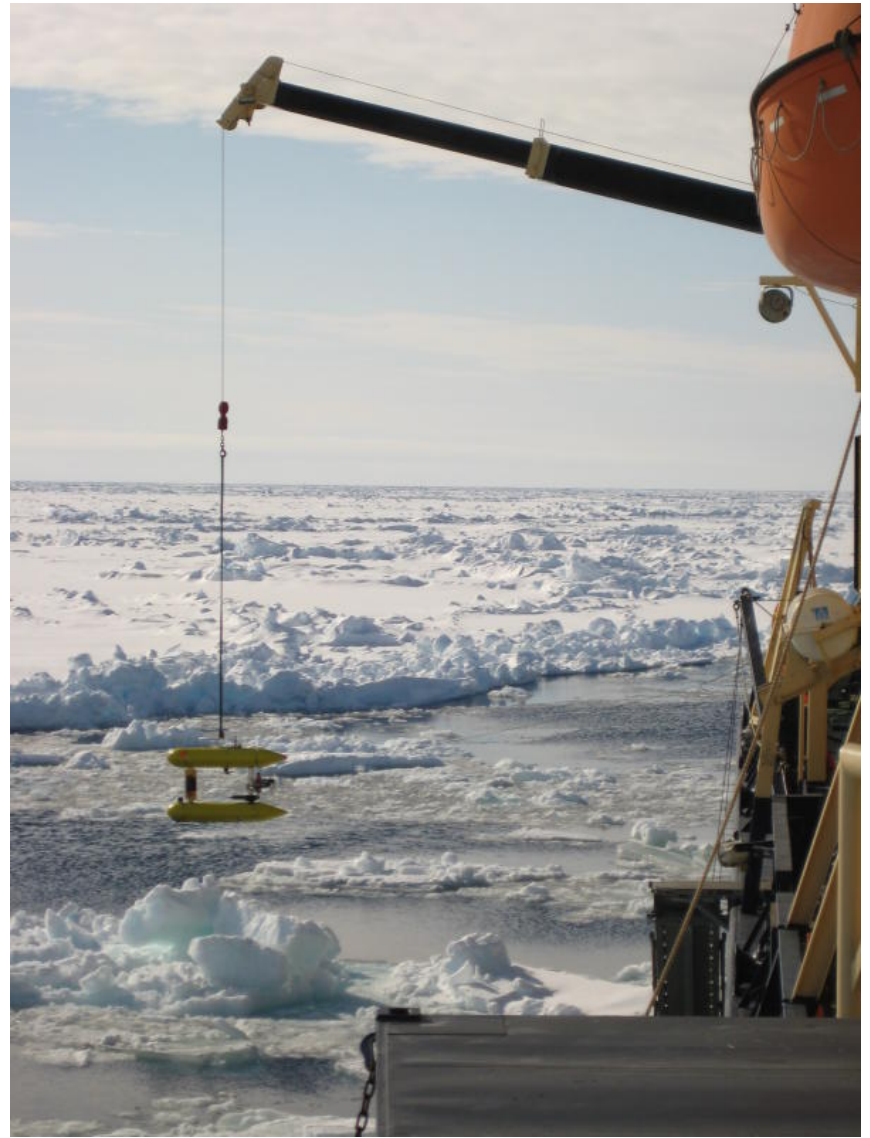

Fig. 1. A typical deployment scenario for the AUV consisted of an open lead or pond into which the vehicle was released. The leads often contained large broken pieces of ice.

holds the potential for the discovery of hydrothermal vent organisms that have been evolving independently for a long period of time.

The harsh conditions associated with year-round ice cover preclude the use of standard oceanographic technologies for mapping, sampling and otherwise exploring this region. The resources required to deploy manned submersibles under-ice in the Arctic are significantly higher than for Autonomous Underwater Vehicles, and most submersible operators consider it too risky to send people under the ice, despite the recent Russian dives near the North Pole. Towed and remotely operated vehicles are also limited in their utility by the nature of ice-breaker operations, which are highly constrained in movement by dense surface ice. AUVs hold 
the best promise for freely working on the seafloor in these limiting conditions.

Based on our experiences during AGAVE with the Puma and Jaguar AUVs, we examine the design constraints associated with under-ice AUV operations (section III), mechanical design (section V), and system software (section VI), and present the results of a typical deepwater mission (section VII) before offering some concluding remarks (section VIII).

\section{RELATED WORK}

AUVs have been used for under-ice exploration in previous expeditions to both the Arctic and the Antarctic polar regions. The Theseus AUV was used to lay optical fibre under the ice in the mid nineties[1]; the Odyssey group[2][3] also conducted expeditions in the Arctic; the British AUTOSUB AUV gathered mid-water column scientific data with forays under the ice in the Antarctic[4]; and various groups have worked in lakes[5] and cenotes[6] as analogs to Arctic and Antarctic exploration. Previous groups have also examined the particularities of operating a vehicle through a hole in the ice[7]. The defining differences between these programs and ours include: a requirement for working near the seafloor in deep $(\sim 4000 \mathrm{~m})$ water; a requirement to deploy in an area that is permanently covered with ice that is drifting at about 0.2 knots for mission durations that do not allow us to maintain an open hole throughout a single dive; a cost per vehicle that is significantly lower than that for most AUVs; and the ability to accommodate a suite of scientific sensors based on the mission at hand.

\section{UNDER-ICE ARCTIC OPERATIONS}

During typical open-water AUV operations the control ship is positioned near the survey site, and an AUV is lowered from the deck and released on its mission. Once the mission is finished, or if a problem occurs, the AUV returns to the surface wherever it happens to be. If possible, the AUV is tracked while it is in the water (and in particular while it is on its way back to the surface). Once it reaches the surface, the vehicle is located visually, with the aid of a radio direction finder (RDF) or another radio-based localization scheme such as GPS coupled with an RF modem. The ship can then be driven to the AUV, where it is recovered.

Such a scenario is ruled out immediately for Arctic operations by the difficulty of finding and recovering an AUV through several meters of ice, and by the restrictions imposed by the ice on ship maneuverability. Underwater tracking becomes essential, rather than just convenient. Moreover it is necessary to be able to actively control the vehicle from the surface to direct it to open leads in the ice. These two requirements lead to significant changes in how the robots are built and used, and in what we as engineers did during the long periods of time that the robots were in the water.

Our basic mode of operation called for us to drive an ice-breaker to an open lead or pond within a kilometer of our area of interest. The availability of leads varied from dive to dive, as shown in Figure 2. An AUV would then be

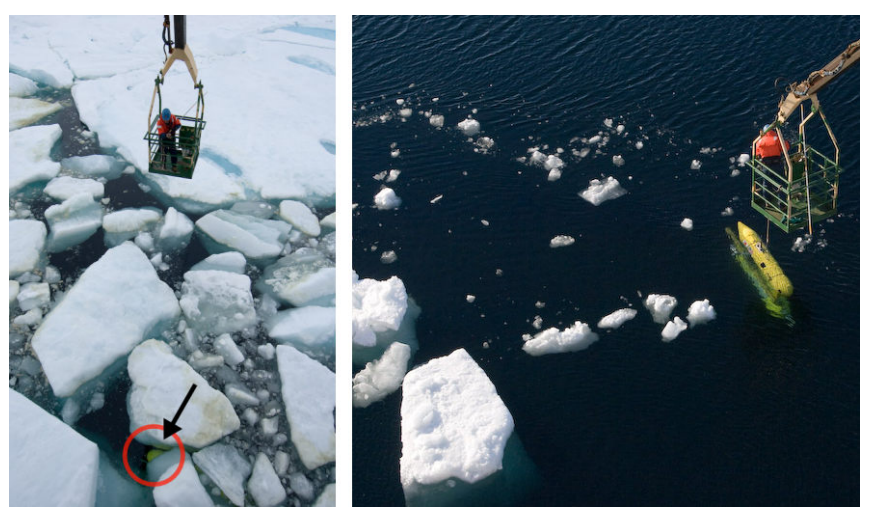

Fig. 2. The size of open leads and density of the ice during AUV recovery varied greatly from dive to dive. Opening a pond sometimes also required moving the ship, temporarily precluding AUV communications. The AUV is barely visible in the left image.

launched through the lead, from which it would follow a preprogrammed mission, navigating primarily using acoustic beacons previously moored to the seafloor and surveyed from the ship's helicopter. As missions could last as long as 24 hours, the open lead used to deploy the AUV would typically drift several kilometers from the dive site, making it unusable for recovery. We thus needed the ability to direct the AUV to a new recovery site, even in case of hardware or software failure, as described in section VI. Each recovery featured a unique and unpredictable set of ice conditions, including acoustic shadowing and multipath from ice floes, and salinity changes caused by surface ice melt leading to ballasting problems. These conditions near the surface precluded standard navigation and communications and posed the risk of a complete loss of a trapped vehicle. It was therefore imperative to retain as much control of the AUV as possible, despite any malfunctions.

\section{Navigation And Acoustic Communications}

Electromagnetic (EM) radiation is quickly absorbed by sea water. A typical radio modem operating in the 900 $\mathrm{MHz}$ band stops functioning entirely as soon as the antenna goes more than a few centimeters below the surface of the ocean. Acoustic communication is the only known wireless communication method that works reliably over long distances through water. While typical surface- or airbased robots might use EM signals for both navigation (i.e. GPS) and communication (i.e. radio modems or $\mathrm{WiFi}$ ), underwater vehicles generally rely on acoustic signalling for both navigation and communication. Puma and Jaguar both use a WHOI MicroModem [8] for long-baseline (LBL) network interrogation and for point-to-point communication between the AUVs and the ship.

\section{A. Navigation}

Since GPS does not work underwater, when georeferenced navigation is necessary a team typically deploys a set of acoustic beacons, forming an LBL network. These beacons are programmed to listen for a short sound pulse at a specific freqency (a "ping"), and respond with a pulse 
at a different frequency. An AUV interrogates the network by generating a query ping, and measuring how much time elapses before it hears the responses from the beacons. These travel times, together with the known locations of the deployed beacons, provide constraints on the possible locations of the robot. For a vehicle with an on-board depth sensor, only two LBL beacons are required to produce a fully-constrained position fix. At the second of the two AGAVE operating sites, for example, we deployed four Benthos LBL beacons from tethers suspended about 150 meters above the sea floor. Each beacon was programmed to listen for a $9 \mathrm{KHz}$ ping, and reply at a unique frequency (one each at 9.5, 10, 10.5 and $11 \mathrm{KHz}$ ). The operating range of each beacon was about seven kilometers, so four beacons in the water gave us the flexibility to survey a fairly large area, as shown in figure 4.

An LBL network such as this is generally sufficient for open-water operation, but in the presence of ice many otherwise easy problems became difficult. The seemingly simple tasks of deploying and surveying the locations of the LBL beacons is complicated by the limited maneuverability of the ship. We were able to work around these problems by using the ship's helicopter for the beacon survey, and in at least one case, for moving LBL beacons onto the ice for direct deployment into the water, rather than from the deck of the ship.

A more tenacious problem is caused by the fact that sound does not move at a constant speed through sea water, leading to errors in pose estimates that can grow to tens of meters on the surface. In open water this is usually not a significant issue, but in ice, errors of this magnitude can render vehicle recovery extremely difficult. In order to compensate for this, we deployed LBL beacons from tethers hanging over the side of the ship during recoveries, and computed independent AUV position estimates on the ship using travel times telemetered from the vehicle (see the next section, and also section VII-B). To add redundancy to our pose estimates, we also made use of direct ranging measurements using a backup beacon onboard the AUV, and by using the MicroModem's built-in ranging mode. Finally, in some situations we determined AUV locations from the ship by passively listening to the robot's LBL interrogations and the network's replies, which provide hyperbolic constraints that can be combined to produce a fix. All of these navigation modalities are discussed in much greater detail in [9].

\section{B. Communication}

Encoding information in a modulated acoustic wave brings a fundamental tradeoff between range and bandwidth. The WHOI MicroModem is capable of using a variety of encodings for transmission, including frequency-shift keying, spreading codes, and block codes with varying degrees of error correction. Since the required operating range cannot be decreased without lowering the surface of the ocean (likely impractical), we chose the highest transmission rate that resulted in reasonably robust communications over the required distances. Puma and Jaguar needed to operate on the order of

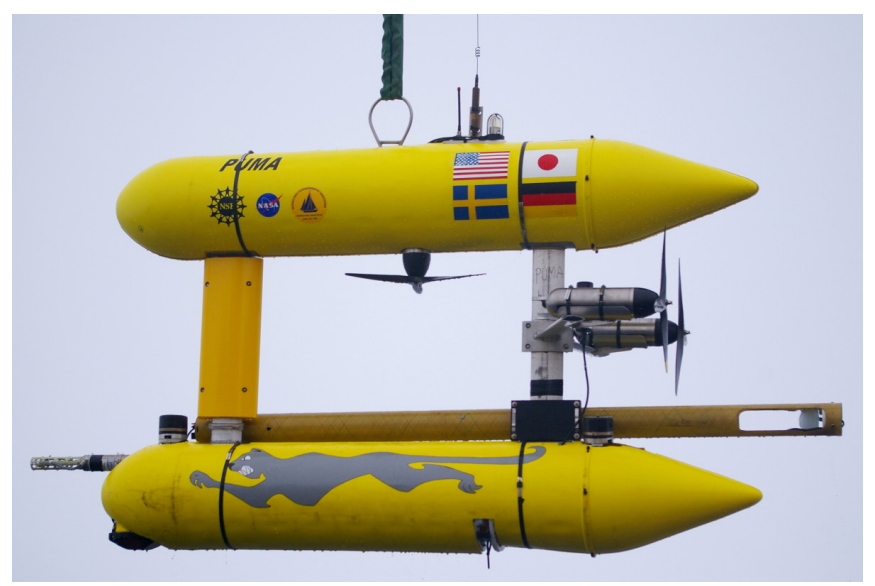

Fig. 3. Puma hangs from the shipboard crane after recovery.

seven to ten kilometers from the ship, so our communications used frequency-shift keying in the regime of 8 to $12 \mathrm{KHz}$, providing a maximum bandwidth of approximately 80 bits per second in 32-byte packets or in 13-bit "mini-packets".

In addition to the extreme bandwidth limitations, the acoustic channel is a shared (broadcast) medium, which implies that collision avoidance must be considered, particularly when the baud rate is so slow. The acoustic channel is also used for LBL navigation, as mentioned above, which further restricts the amount of communication traffic that can take place. For simplicity, we used time-division multiplexing (TDMA) to prevent collisions, and adapted our operations as necessary to cope with the relative scarcity of data available from the AUVs. On a typical deployment, we used a 90second TDMA cycle, where each cycle contains a single 32-byte packet sent in each direction, as well as three LBL network interrogations. This resulted in an effective uplink bandwidth of less than 3 bits per second. Each uplink (robot to ship) packet contained vehicle state information, including pose estimate, mission goal information, and most-recent LBL travel times. The downlink (ship to robot) packets were only used during vehicle recovery, and contained goal positions for the robot to try to reach before surfacing.

\section{Mechanical Design}

The two AUVs are identical in their system design, differing only in their sensor payload. They are based on the proven design of the Seabed[10] AUV. Our design constraints included a requirement for inexpensive vehicles with the ability to accommodate a suite of sensors. Puma is shown in Figure 3.

The vehicles consist of two hulls connected by a pair of aluminum spars. Each hull contains a single large pressure housing, and syntatic foam for ballast. Most of the negative buoyancy is in the lower hull, while most of the positive bouyancy is in the upper hull; this makes the vehicle naturally stable in roll and pitch and allows for a large meta-centric height. We selected foam and pressure housings adequate for a maximum depth of 6000 meters; in practice our operating depth was about 4000 meters. The lower 
pressure housing contains the batteries and the fiber optic gyro, while the upper pressure housing contains the computer which controls the vehicle. Other sensors are either contained in their own pressure housings, or are in sealed glass spheres when an opaque housing could not be used (for example in the case of the camera's strobe). Fully assembled, the vehicles are about 2 meters long, 1.5 meters tall, and weigh about 250 kilograms in air.

The vehicles are driven using three thrusters with propellors mounted to the shafts. Two thrusters are mounted between the two hulls at the aft of the vehicles, and are used in a differential-drive configuration, providing both foward thrust and heading control. The third thuster, mounted to the top hull, provides vertical thrust. The propellors turn at a maximum of 150 RPM and consume about 100 watts of power each at that speed, providing a working forward velocity of about 35 centimeters per second, and a vertical velocity of 20 centimeters per second (12 meters per minute).

The vehicles carry 64 lithium ion batteries, providing 6 $\mathrm{kWHr}$ of capacity, and allowing at least 24 hours of operations depending upon the hotel load of the sensors. Without descent weights, the AUVs can spend as much as half of their power budget during the descent and ascent portions of a dive, which, while suboptimal, reduces complexity and improves safety.

The individual hull shapes were chosen to minimize drag. Subsequent to the hull design, however, we made a systems level decision to run the vehicles with a downward pitch of about fifteen degrees. This allows the main thrusters to assist the vertical thruster somewhat in maintaining depth.

The thrusters and most of of the sensors are controlled via RS-232. Using RS-232 allows us to use standard through-hull connections on the pressure housings, and prevents the need for wet twisted pair wire. Jaguar carries a gigabit ethernet camera, but the through-hull connections are only reliable enough for 100 megabit speeds, and only using twisted-pair wire. For gigabit speeds we would switch to fiber, though other restrictions on camera usage prevented this from being necessary. For example, our strobe needs a few seconds to recharge after each image is taken, so our effective frame rate is only about one image every three seconds.

Under-ice operations required additional backup equipment not typically used in open ocean AUV deployments. The two vehicles carried a completely separate acoustic beacon to which we could compute ranges even in the event that the main vehicle power was lost. They also carried an isolated radio-frequency beacon that could be used to locate vehicles trapped under the ice - these beacons were expressly designed for for search and rescue of human avalanche victims, but they also work well for finding robots with depleted batteries.

\section{A. Sensor Suite}

While Puma and Jaguar are outfitted with identical thrusters and navigation sensors, they differ in their science payloads and in how they are used. Both vehicles carry standard oceanographic sensors for measuring water temperature, conductivity, pressure, salinity, and oxidation potential ("eH"), as well as navigation sensors, including a 3axis fiber optic gyro, doppler velocity log, and depth sensor. Both vehicles also carry a WHOI MicroModem, described above. Puma (the "Plume Mapper") carries sensors designed for water-column surveys, most notably a pair of optical backscatter sensors for measuring the amount of particulate matter suspended in the water. Jaguar carries sensors suited to seafloor surveys, including a downward-facing optical camera, an imaging sonar, and a magnetometer.

\section{VEHICle Software}

The onboard software is divided into two distinct processes, which run on a PC/104 computer under Linux. One of these, the control process, communicates directly with the vehicle hardware, sending control commands to the thrusters, computing pose estimates from the navigation sensors, and logging data from the science sensors. The other process controls mission execution, interpreting telemetry provided by the control process and following a user-supplied script to carry out the survey. In order to maximize the robustness of the software, we implemented several failsafes to prevent loss of vehicle control. In particular, we implemented a "safe mode," in which the robot will cancel all of its navigation goals, start to float slowly toward the surface under its own positive buoyancy, and listen for commands sent acoustically from the ship. This mode is engaged whenever:

- The on-board computer reboots (e.g. because of a power fault).

- The control process exits (e.g. because of a memory fault) - this causes a reboot triggered by an expiring watchdog timer.

- An abort is sent acoustically from the ship.

- An internal mission abort is triggered (e.g. by a maximum depth being exceeded, or by a critical sensor failing).

The safe mode ensures that the robot remains in a controllable state as much as possible. Once engineers have assessed the situation, they can send position and depth goals to the AUV to control the ascent. The only situation in which a robot floats to the surface completely passively is when the on-board batteries have been depleted.

If a mission completes normally, the robot ascends under power to a pre-determined depth (typically 200 meters), after which it holds position to listen for new goal directions sent acoustically. Because the robot passively rises as slowly as 6 meters per minute, and actively at around 12 meters per minute, there is adequate time to find a lead for recovery, move the ship, and re-establish acoustic communications with the AUV to "drive it home."

\section{PERFormance AND Results}

\section{A. Overall Results}

During the summer of 2007, we made two trips to the Arctic. The first trip was a 14-day engineering trial to ice just north of Svalbard, and the second was the 6-week expedition to two sites along the Gakkel Ridge, at 85 degrees north 


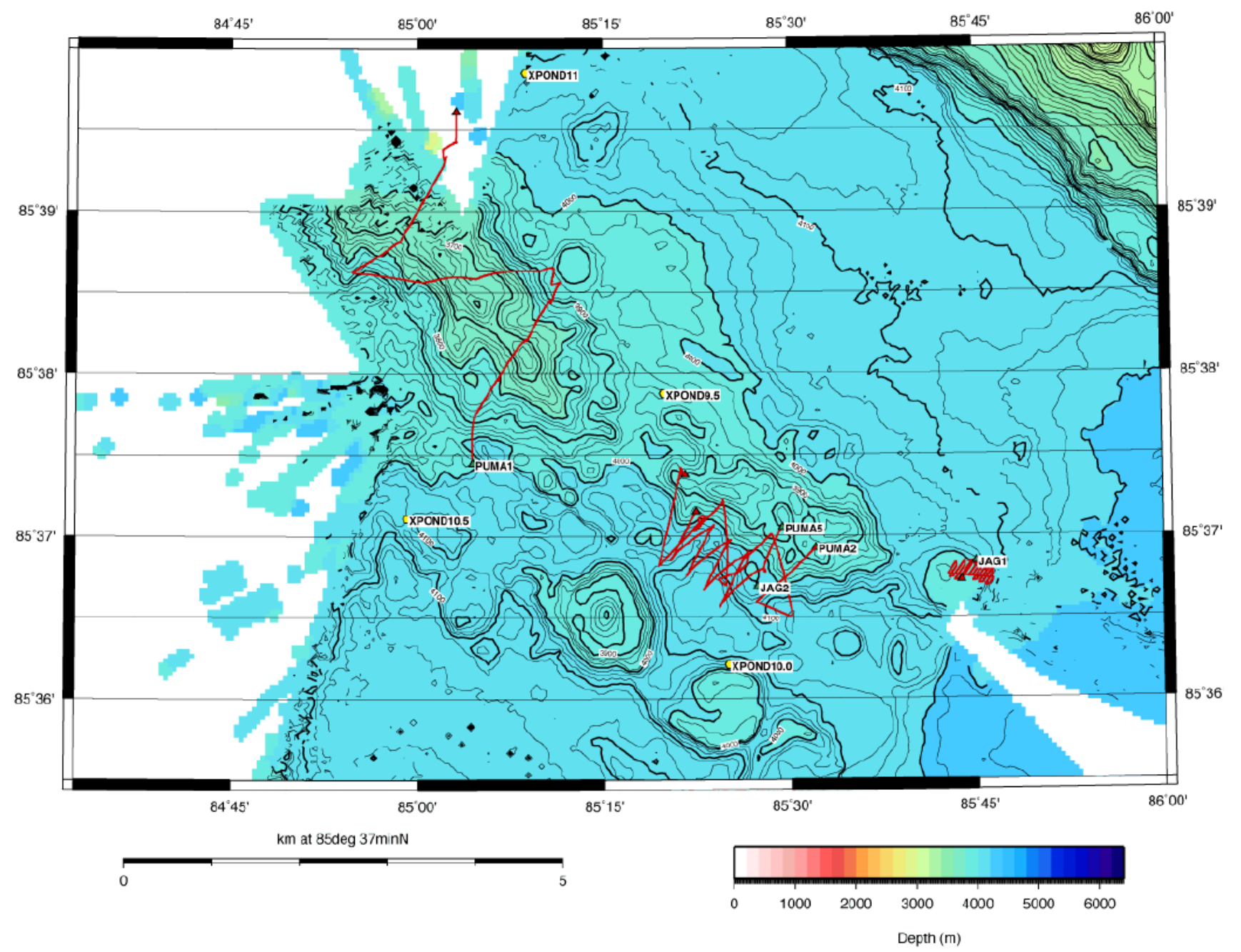

Fig. 4. Actual tracklines flown during AUV missions superimposed on local bathymetry.

latitude. During the course of the expedition, we deployed Puma six times, and deployed Jaguar three times. The mission track followed by the AUV in each case is shown in Figure 4. In addition to the AUVs, the science team made use of a towed sled with sampling capabilities called CAMPER, a traditional oceanographic CTD carousel, and a network of seismographs deployed directly onto the ice. The crew of the ship, the Swedish icebreaker Oden, also made use of ice drift buoys to estimate the motion of the ice pack. The details of our scientific results have been described in [11][12].

\section{B. A Typical Dive}

The second Puma dive, PUMA0001, was primarily for hydrothermal plume detection and localization, using the $\mathrm{eH}$, CTD, and optical backscatter sensors. The mission called for the Puma AUV to perform 3 transects of a $1.9 \mathrm{~km}$ by $1.9 \mathrm{~km}$ area while 'towyo'-ing; oscillating in depth between $3200 \mathrm{~m}$ and $3550 \mathrm{~m}$ through the estimated depth of a non-buoyant hydrothermal plume. Figure 5 shows the depth of the AUV against mission time.

AUV deployment was performed as shown in Figure 1. The AUV was attached to the shipboard crane, and lowered

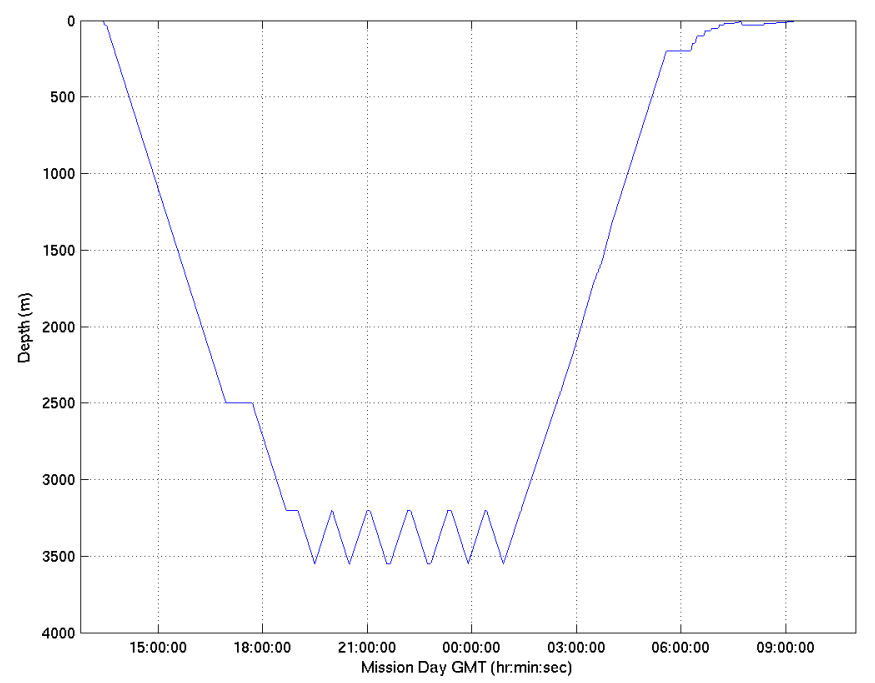

Fig. 5. AUV depth versus time for AGAVE PUMA0001 mission. Note the up and down 'Towyo' motion once the AUV reaches the operating depth. 


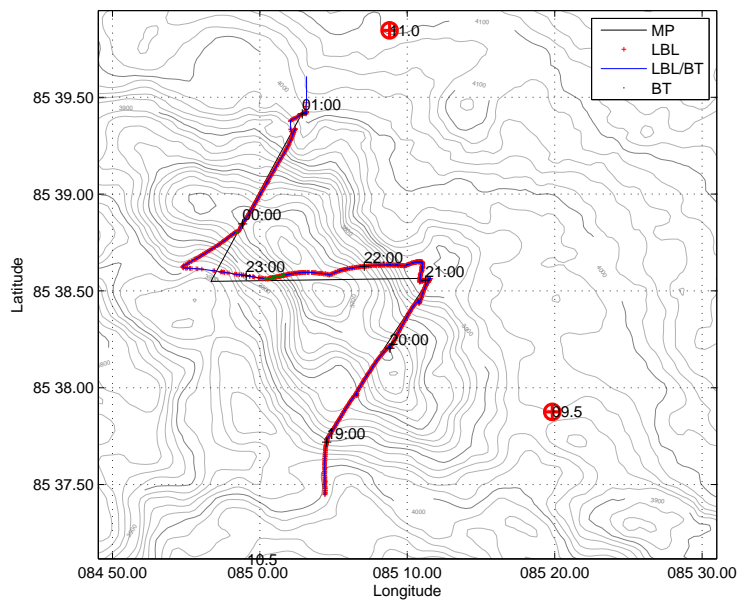

Fig. 6. The tracklines run by the AUV during the AGAVE PUMA0001 mission. The planned tracklines are shown in solid black. The red crosses show LBL fixes, and the green dots show locations with a bottom track fix.

into the water. Pre-dive hardware and software readiness checks were performed, including adjusting the ballast to compensate for changes in the scientific payload. During ballasting, we consulted the amount of energy used by the vertical thruster during the previous dive as an indicator of the ballast at depth. We attempted to ballast the vehicles so that they were one kilogram positive when at depth. In some cases icemelt caused a decrease in salinity on the surface and resulted in the vehicle being neutrally or very slightly negatively buoyant when near the surface of the water. After starting the mission, we would detach the crane's tether from the AUV, which would then start to dive.

At $30 \mathrm{~m}$ depth, the AUV paused to provide an opportunity for an acoustic abort if the telemetry suggested anything was amiss early in the mission. The vehicle then continued on to $2500 \mathrm{~m}$, where it transited horizontally until it was directly above its first waypoint. While the Arctic provided an excellent environment for acoustic communications, transiting well above the seafloor ensured that LBL transponders were not shadowed by the mountainous bathymetry. After reaching the first trackline waypoint, the vehicle dove to $3200 \mathrm{~m}$ and began its 'towyo' behavior.

The AUV was configured to use doppler bottom track for navigation when possible, and to use LBL navigation when bottom track was unavailable. Since this dive was run primarily in the middle of the water column, LBL navigation was primarily used as shown in Figure 6. After completing the mission, the vehicle ascended to $200 \mathrm{~m}$ and waited for further waypoints transmitted acoustically from the Oden. Engineers onboard the ship computed the correct waypoints to use, and sent them to Puma following the robot's normal communications TDMA cycle. On this dive, Puma's chemical sensors detected a number of anomalies consistent with a non-buoyant hydrothermal plume, as shown in Figure 7.

After completing the tracklines, the AUV rose to a depth of $200 \mathrm{~m}$. The Oden was approximately $750 \mathrm{~m}$ horizontal
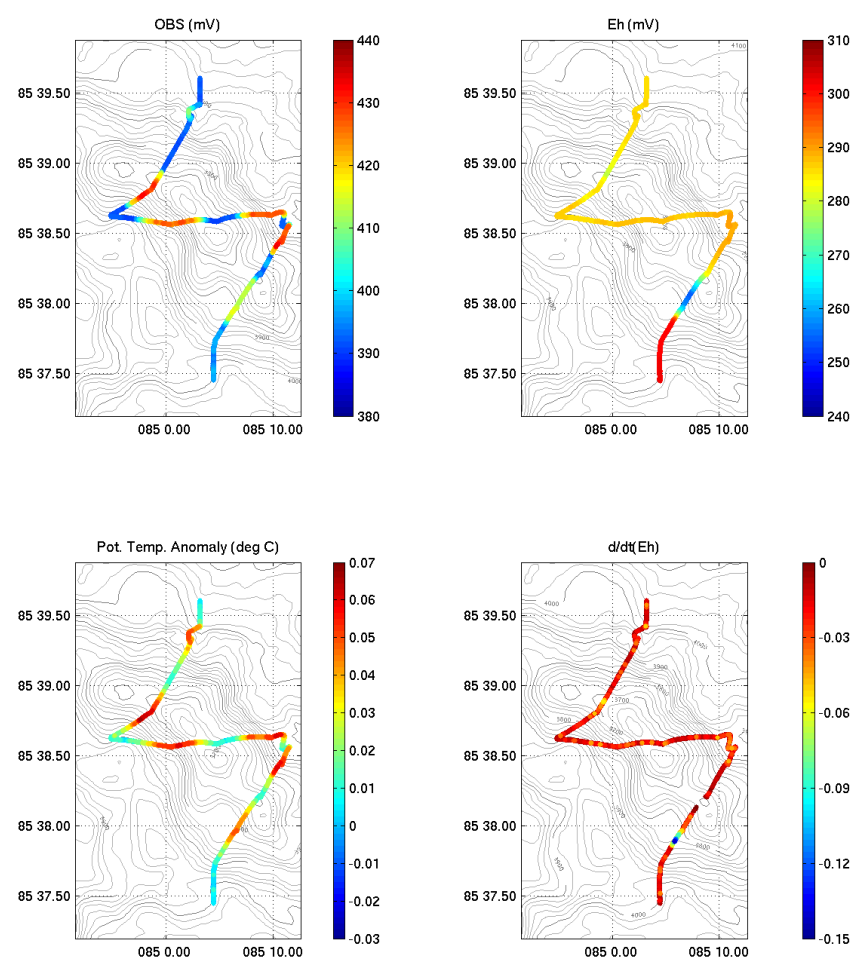

Fig. 7. Chemical sensor traces overlaid on mission track. There is an eH anomaly indicated by the blue coloring in the lower right subplot.

distance away from the AUV, next to an opening in the ice pack where the AUV could surface. Ice drift caused the ship to move away from the AUV at up to 25 centimeters per second, which required the AUV to drive for over two hours "chasing" the ship before catching up. During this time, the AUV was gradually brought to a depth of $30 \mathrm{~m}$ as it grew progressively closer. The AUV moves faster in shallower water, which is captured and carried along with the drifting ice, but communications are less reliable at shallow depths, due to acoustic multipath caused by the sea ice. When the AUV reached the ship, the opening had become clogged with ice. To clear the recovery pond, the AUV was directed to hold depth at 30m while the shipboard LBL transponders and telemetry transducer were removed from the water. After the icebreaker had cleared the hole of ice, the vehicle ascended to a few meters depth and drove straight towards the ship from about $100 \mathrm{~m}$ away. At a range of about $30 \mathrm{~m}$, the vehicle was spotted from the helicopter deck and brought to the surface.

The AUV surfaced in a section of slush ice near the edge of the pool. After dives, we recovered the AUVs using either the Oden's small boat, or a basket attached to a crane lowered over the side of the ship, depending on the amount of open water and the proximity of the AUV to the Oden. On two occasions we recovered Jaguar using the ship's helicopter as the AUV was too far away to be reached efficiently by the Oden or its small boat.

\section{CONCLUSIONS}

During the summer of 2007, we demonstrated that autonomous underwater vehicles can be effectively used for scientific research under the permanent ice pack. We re- 


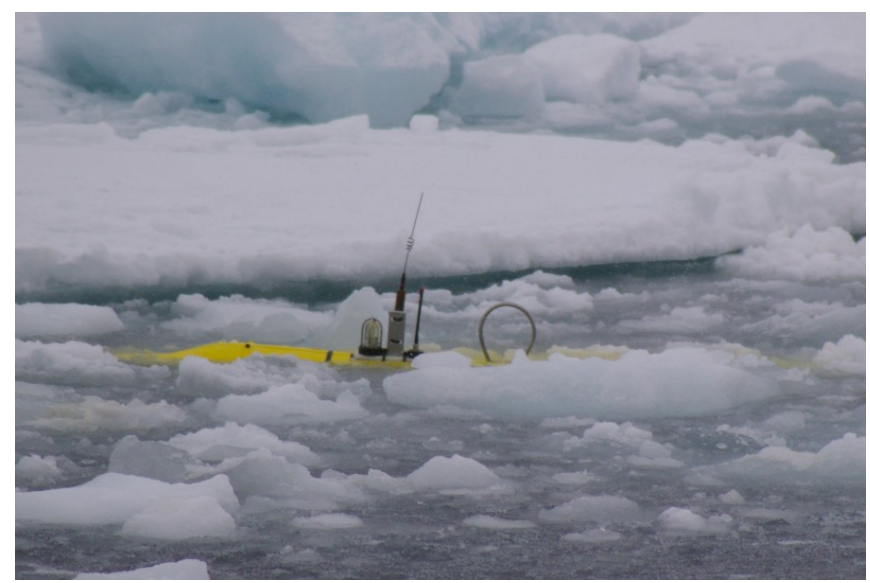

Fig. 8. Puma surfaces in ice near the pond edge after PUMA0001.

fined traditional AUV design and operations as necessary to reliably deploy and recover vehicles in the harsh Arctic environment. The AGAVE expedition can be thought of as a baseline for future sub-ice robotic exploration, in the Arctic, the Antarctic, and even on other planetary bodies. Indeed, the AGAVE expedition was funded in part by NASA's Astrobiology Science and Technology for the Exploration of Planets program (ASTEP), with the explicit goal of learning more about how robotic technology might be used to explore Europa's ice-covered ocean. Among many lessons learned, the fundamental requirement for reliable acoustic communications should be taken as a starting point for future development of sub-ice vehicles.

In addition to the advancement of AUV technology, the AGAVE expedition resulted in several scientific discoveries in its own right, including unexpected evidence for deep explosive volcanism[13], a chain of undersea volcanoes and several still-to-be-analyzed bacterial mats. These discoveries further validate the use of robotic technology for the exploration of the sea floor.

Now that we have a grasp of how to effectively use AUVs under the ice pack, future work will focus on improving communications and navigation, with an eye toward a general improvement of operational efficiency. In particular, since the AGAVE trip, we have increased the use of ship-to-vehicle packets significantly. We use synchronized clocks onboard the ship and vehicle, and send GPS fixes from the ship, which can be combined with packet travel times to compute running position fixes on the AUV [14]. This in theory could allow for operations that require no deployed LBL infrastructure at all. We have also started to investigate how ultra-low bandwidth acoustic communication with AUVs can accelerate scientific decision-making so that investigators need not wait for one dive to end before another can begin [15].

At a more mundane level, several simple changes using proven technology should be taken, including the use of descent weights to reduce the amount of time and energy spent reaching the sea floor (ascent weights are less advisable, since a large amount of positive buoyancy would make maneuvering an AUV to an open lead quite problematic). Finally, a more complicated improvement would be to deploy multiple AUVs in the water simultaneously. Toward the end of the AGAVE expedition, we deployed the CTD carousel during AUV dives, but we never had both AUVs in the water at the same time. Since then, we have started experiments with multiple-vehicle operations, but none yet under ice.

In summary, the technology and expertise needed to explore the ice-covered oceans now exists. More development is needed to bring the technology to maturity, and to adapt it for exploration further afield, but the positive results of the AGAVE expedition show that the use of robots is effective, inexpensive, and much less risky than manned exploration.

\section{REFERENCES}

[1] J. Thorleifson, T. Davies, M. Black, D. Hopkin, and R. Verrall, "The Theseus autonomous underwater vehicle: A Canadian success story," in Proc. IEEE/MTS Oceans Conference and Exhibition, 1997, pp. 1001-1008.

[2] J. Bellingham, C. Chryssostomidis, M. Deffenbaugh, J. Leonard, and H. Schmidt, "Arctic under-ice survey operations," in Proc. Intl. Symposium on Unmanned Untethered Submersible Technology, University of New Hampshire, September 1993, pp. 50-59.

[3] R. McEwen, H. Thomas, D. Weber, and F. Psota, "Performance of an AUV navigation system at Arctic latitudes," IEEE J. Oceanic Eng., vol. 30, no. 2, pp. 443-454, 2005.

[4] G. Griffiths, "AUTOSUB missions beneath polar ice: Preparations and experience," in Seminar at the University of South Florida, May 2004.

[5] A. Forrest, H. Bohm, B. Laval, D. Reid, D. Andersen, E. Magnusson, and M. Doble, "Small AUV deployment under ice: Pavilion lake, B.C., Canada (a case study)," Geophysical Research Abstracts, vol. 9, 2007.

[6] N. Fairfield, D. Jonak, G. A. Kantor, and D. Wettergreen, "Field results of the control, navigation, and mapping systems of a hovering AUV," in Intl. Symp. on Unmanned Untethered Submersible Technology, 2007.

[7] R. Bono, G. Bruzzone, M. Caccia, E. Spirandelli, and G. Veruggio, "Romeo goes to Antarctica," in Proc. IEEE Oceans Conference, vol. 3, Nice, France, September 1998, pp. 1568-1572.

[8] S. Singh, M. Grund, B. Bingham, R. Eustice, H. Singh, and L. Freitag, "Underwater acoustic navigation with the WHOI Micro Modem," in Proc. IEEE/MTS Oceans Conference and Exhibition, Boston, USA, 2006.

[9] M. Jakuba, C. Roman, H. Singh, C. Murphy, C. Kunz, C. Willis, T. Sato, and R. Sohn, "Field report: Long-baseline acoustic navigation for under-ice AUV operations," J. Field Robotics, vol. 25, no. 8, July 2008.

[10] H. Singh, A. Can, R. Eustice, S. Lerner, N. McPhee, O. Pizarro, and C. Roman, "Seabed AUV offers new platform for high-resolution imaging," EOS, Transactions of the AGU, vol. 85, no. 31, pp. 289,294295, August 2004.

[11] R. A. Sohn, H. Edmonds, S. Humphris, T. Shank, H. Singh, B. Ericsson, U. Hedman, M. Jakuba, C. Kunz, B. Larsson, B. Liljebladh, J. Linder, C. Murphy, K. Nakamura, C. Pontbriand, T. Sato, V. Schlindwein, C. Strane, M. Tausendfreund, L. Upchurch, C. Willis, and P. Winsor, "Scientific scope and summary of the Arctic Gakkel vents (AGAVE) expedition," in EOS, Transactions of the AGU, vol. 88, 2007.

[12] T. M. Shank, J. Bailey, H. Edmonds, P. Forte, E. Helmke, S. Humphris, J. Kemp, K. Nakamura, R. A. Sohn, H. Singh, and C. Willis, "Biological and geological characteristics of the Gakkel ridge," in EOS, Transactions of the AGU, vol. 88, 2007.

[13] R. Sohn, C. Willis, S. Humphris, T. Shank, H. Singh, H. Edmonds, C. Kunz, U. Hedman, E. Helmke, M. Jakuba, B. Liljebladh, J. Linder, C. Murphy, K. Nakamura, T. Sato, V. Schlindwein, C. Stranne, M. Tausenfreund, L. Upchurch, P. Winsor, M. Jakosson, and A. Soule, "Explosive volcanism on the ultraslow-spreading Gakkel ridge, Arctic Ocean," Nature, June 2008.

[14] R. M. Eustice, L. L. Whitcomb, H. Singh, and M. Grund, "Experimental results in synchronous-clock one-way-travel-time acoustic navigation for autonomous underwater vehicles," in Proc. IEEE Intl. Conf. Robotics and Automation, Rome, Italy, Apr. 2007.

[15] C. Murphy and H. Singh, "Human guided autonomy for acoustically tethered underwater vehicles," in Proc. IEEE Oceans Conference, 2008 (accepted). 